\title{
Fabrication and in situ functionalisation of mesoporous silica films by the physical entrapment of functional and responsive block copolymer structuring agents
}

\author{
Jessica C. Tom, ${ }^{a}$ C. Appel ${ }^{b}$, Annette Andrieu-Brunsen*a \\ a Ernst-Berl Institut fu"r Technische und Makromolekulare Chemie, Technische Universität Darmstadt, Alarich-Weiss-Straße \\ 12, Darmstadt 64287, Germany \\ b Institute of Condensed Matter Physics, Technische Universität Darmstadt, Hochschulstraße 8, Darmstadt 64289, Germany. \\ E-mail: andrieu-brunsen@smartmem.tu-darmstadt.de
}

Electronic Supplementary Information (ESI) available: All materials and methods are described in detail, with additional results and discussion provided. See DOI: 10.1039/c9sm00872a

Stimuli-responsive mesoporous silica films were prepared by evaporation-induced self-assembly through the physical entrapment of a functional block copolymer structuring agent, which simultaneously serves to functionalise the mesopore. These polymer-silica hybrid materials exhibit remarkable ionic permselectivity under highly filled conditions, and offers the potential for local polymer functionalisation for enhanced and tuneable ionic permselectivity. This innovative and simple approach for the in situ functionalisation of mesoporous silica has the potential to improve how we approach the design of complex architectures at the nanoscale for enhanced transport, and thus relevant for a variety of technologies based on molecular transport in nanoscale pores including separation, sensing, catalysis, and energy conversion

\section{Introduction}

Ordered mesoporous silica (OMS) has attracted growing research interest in a wide range of fields, offering attractive and tuneable properties for catalysis, sensing and separation, optics, and in drug delivery. ${ }^{1-5}$ Generally, OMS is synthesised through the co-assembly of either surfactants or amphiphilic block copolymers (BCPs), which act as templates to afford a desired structure in the presence of an inorganic precursor (e.g., TEOS). ${ }^{1}$ The formed structure is then consolidated through a stabilising thermal treatment, and the template removed by calcination at elevated temperatures or by solvent extraction. ${ }^{6}$ In the case of solvent extraction, the potential for template recycling is appealing to create more sustainable materials. ${ }^{7}$

The most widely applied soft templates currently encompass a number of small surfactants (e.g., CTAB) and commercially available amphiphilic triblock copolymers (e.g., Pluronic ${ }^{\circ} \mathrm{F}-127$ ), which offer limited accessible pore sizes of less than $10 \mathrm{~nm} \cdot{ }^{4,8}$ Although large-pore OMS with pore diameters up to $50 \mathrm{~nm}$ using non-pluronic amphiphilic BCPs as templates have been reported. ${ }^{9}$ In addition, these templates are removed after film formation, and therefore do not endow the pore wall with any functionality.

The most widely applied methods to endow the pore wall with specific functionality and widen their application scope are co-condensation of functional organosilanes, and post-grafting polymers to the mesochannel surface. ${ }^{10,11}$ The drawbacks of both approaches are already highly reported on: pore blocking, inhomogeneous functionalisation, and/or low degree of functionalisation, as well as being quite laborious, requiring multiple steps. ${ }^{6,12}$

Polymer functionalisation remains the best approach to adjust the properties of OMS; however, grafting-to presents limited grafting density due to sterics, and grafting-from suffers from low 
molecular weight grafts due to faster polymerisation kinetics and increased termination under confinement. ${ }^{13,14}$

An approach that remains largely unexplored is the use of functional, and ideally responsive, polymers to template the formation of mesoporous silica, which can also be retained within the mesopores to modify its properties. To-date, most reports rely on PEO-based block copolymers similar to the commercial pluronics, to prepare functional hybrid materials in a 1-step process. ${ }^{4,15-17}$ This approach relies on the strong interaction between the PEO block and the silica precursors during the sol-gel process, ${ }^{4,11}$ resulting in the polymer being anchored within the pore wall. As an example, Bathfield et al., ${ }^{6}$ synthesised PEO- $b$-PNIPAAm from a PEO macroinitiator and subsequent RAFT polymerisation, and applied them as templates to create thermosensitive drug-loaded OMS. The mesoporosity of these materials was created by water washing below the LCST of PNIPAAm. Silane end-functionalised polymers have also been incorporated within the sol; ${ }^{18}$ however, template removal is required to produce responsive OMS, and is limited to low molecular weight polymers.

Herein, we report the synthesis of amphiphilic PS- $b$-PAA BCPs with varying chain lengths and block ratios via single- electron transfer living radical polymerisation (SET-LRP). These functional amphiphilic block copolymers were then used to both structure and functionalise the pores of OMS films through evaporation induced self-assembly (EISA) and polymer entrapment. This novel strategy is illustrated schematically in Figure 1, leading to unprecedented pore filling with a high molecular weight block copolymer, and further offers the potential for local polymer functionalisation. To the best of our knowledge, this is the first example studying the ionic permselectivity of mesoporous silica presenting high filling with a functional block copolymer not physically attached to the pore wall. Furthermore, we expect this report will alter how new functional porous materials are designed in the future, offering the material scientist unprecedented control over local functionality and surface patterning through multilayering to, for example, effectively print complex material architectures for a range of applications from lab-on-chip devices, separation and sensing, and even in biomedicine.

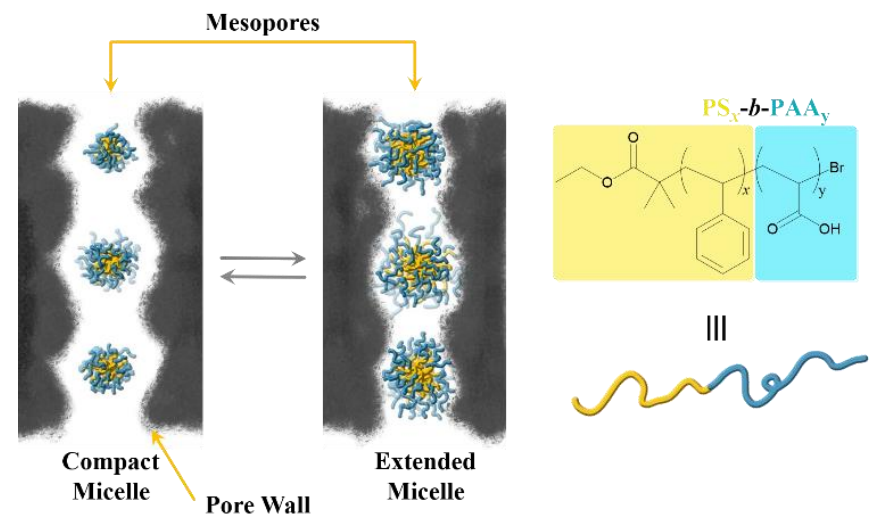

Figure 1 Schematic depiction of the prepared stimuli-responsive mesoporous silica films containing an amphiphilic block copolymer structuring agent that is entrapped within the mesopores for enhanced ionic permselectivity control.

\section{Results and Discussion}

A series of well-defined PS- $b$-PAA BCPs were synthesised via SET-LRP of styrene (S), and subsequent chain-extension and deprotection of tert-butyl acrylate to yield acrylic acid (AA) moieties. The polymer synthesis and detailed characterisation is given in the ESI. After testing their self-assembly behaviour in THF/water mixtures via UV-Vis spectroscopy and dynamic light scattering (DLS) (Figure S3 and S4), they were deemed suitable candidates to template OMS materials in agreement with previous studies 
structured with similar block copolymers of styrene with acrylic acid, ${ }^{19}$ methacrylic acid, ${ }^{20}$ and more commonly with PEO. ${ }^{17}$

Table 1 Summary of the prepared amphiphilic BCP properties, as well as the corresponding film properties (i) before and (ii) after template removal by an additional thermal treatment at $350^{\circ} \mathrm{C}$.

\begin{tabular}{|c|c|c|c|c|c|c|c|}
\hline \multicolumn{8}{|c|}{ Amphiphilic block copolymer template properties: } \\
\hline \multicolumn{2}{|l|}{ Entry* } & \multicolumn{2}{|l|}{$\mathrm{A}$} & \multicolumn{2}{|l|}{$B$} & \multicolumn{2}{|l|}{$C$} \\
\hline $\mathrm{NMR}^{\mathrm{a}}$ & $\begin{array}{l}\text { BCP template } \\
\mathrm{M}_{\mathrm{n}, \mathrm{th}}\left(\mathrm{g} \mathrm{mol}^{-1}\right) \\
\mathrm{M}_{1} / \mathrm{M}_{2}\end{array}$ & \multicolumn{2}{|l|}{$\begin{array}{l}\mathrm{PS}_{38}-b-\mathrm{PAA}_{46} \\
7,465 \\
1.2 \\
\end{array}$} & \multicolumn{2}{|l|}{$\begin{array}{l}\mathrm{PS}_{38}-b-\mathrm{PAA}_{100} \\
11,360 \\
0.58 \\
\end{array}$} & \multicolumn{2}{|l|}{$\begin{array}{l}\mathrm{PS}_{60}-b-\mathrm{PAA}_{84} \\
12,555 \\
1.1\end{array}$} \\
\hline $\mathrm{SEC}^{\mathrm{b}}$ & $\begin{array}{l}\mathrm{M}_{\mathrm{n}, \mathrm{SEC}}\left(\mathrm{g} \mathrm{mol}^{-1}\right) \\
\oslash\end{array}$ & \multicolumn{2}{|l|}{$\begin{array}{l}12,780 \\
1.08\end{array}$} & \multicolumn{2}{|l|}{$\begin{array}{l}20,950 \\
1.12\end{array}$} & \multicolumn{2}{|l|}{$\begin{array}{l}15,450 \\
1.22 \\
\end{array}$} \\
\hline $\mathrm{DLS}^{\mathrm{c}}$ & $\begin{array}{l}\text { Zave }(\mathrm{nm}) \\
\mathrm{PDI}\end{array}$ & \multicolumn{2}{|l|}{$\begin{array}{l}413 \pm 12 \\
0.27\end{array}$} & \multicolumn{2}{|l|}{$\begin{array}{l}344 \pm 22 \\
0.53\end{array}$} & \multicolumn{2}{|l|}{$\begin{array}{l}377 \pm 14 \\
0.06\end{array}$} \\
\hline \multicolumn{8}{|c|}{ Film properties (i) before and (ii) after template removal: } \\
\hline Entry* & & (i) & (ii) & (i) & (ii) & (i) & (ii) \\
\hline TEM & $d_{\text {pore }}(n m)$ & $3.9 \pm 0.6$ & --- & $7.1 \pm 0.8$ & --- & $3.8 \pm 0.7$ & --- \\
\hline Ellipsometry & $\begin{array}{l}\mathrm{d}_{\text {ave }}(\mathrm{nm}) \\
\mathrm{n}_{\text {ave }} \\
\mathrm{V}_{\text {pore }}(\%) \\
\text { Shrinkage (\%) }\end{array}$ & $\begin{array}{l}90 \pm 7 \\
1.47 \pm 0.01 \\
--- \\
--\end{array}$ & $\begin{array}{l}79 \pm 6 \\
1.21 \pm 0.00 \\
52 \pm 1 \\
11 \pm 7\end{array}$ & $\begin{array}{l}123 \pm 10 \\
1.51 \pm 0.01 \\
--- \\
---\end{array}$ & $\begin{array}{l}95 \pm 5 \\
1.23 \pm 0.01 \\
48 \pm 2 \\
23 \pm 1\end{array}$ & $\begin{array}{l}129 \pm 1 \\
1.52 \pm 0.01 \\
--- \\
---\end{array}$ & $\begin{array}{l}120 \pm 10 \\
1.16 \pm 0.00 \\
64 \pm 1 \\
7 \pm 8\end{array}$ \\
\hline Wettinge & $\mathrm{CA}\left({ }^{\circ}\right)$ & $76 \pm 3$ & $11 \pm 6$ & $85 \pm 5$ & $34 \pm 7$ & $82 \pm 1$ & $13 \pm 7$ \\
\hline
\end{tabular}

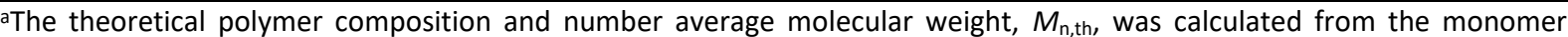
conversion determined by ${ }^{1} H$ NMR. $M_{1}$ and $M_{2}$ correspond to the molecular weight of the hydrophobic and hydrophilic block, respectively. ${ }^{\mathrm{b}} \mathrm{M}_{\mathrm{n}, \mathrm{SEC}}$ and $\Theta$ were determined prior to hydrolysis of the tert-butyl ester groups to acrylic acid by SEC (THF, PS standards). 'DLS was performed in Milli-Q water at a concentration of $1 \mathrm{mg} \mathrm{mL}^{-1}$. ${ }^{\mathrm{d}}$ The average diameter, $d_{\text {ave, }}$ and refractive index, $n_{\text {ave, }}$ arise from 3 measurements recorded using ellipsometry (r.H. $\left.=15 \%\right)$. The volume porosity, $V_{\text {pore, }}$ was calculated according to the Brüggemann effective medium approximation. ${ }^{21,22}$ The film shrinkage upon heating to $350^{\circ} \mathrm{C}$ was calculated

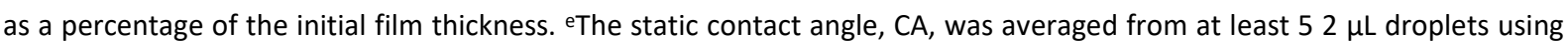
the sessile drop method.

\section{Film preparation}

The synthesised PS- $b$-PAA functional amphiphilic BCPs were then applied as structuring agents in a typical precursor formulation (TEOS:BCP:THF: $\mathrm{H}_{2} \mathrm{O}: \mathrm{HCl}=1: 0.0075: 40: 10.8: 0.28$ ), and dip-coated onto various substrates at a withdrawal speed of $2 \mathrm{~mm} \mathrm{~s}^{-1}$, a relative humidity (r.H.) of $50 \%$, and a temperature of $25^{\circ} \mathrm{C}$. The silica framework was then consolidated with a stabilising thermal treatment after drying for $24 \mathrm{~h}: 60^{\circ} \mathrm{C}$ for $1 \mathrm{~h}, 120^{\circ} \mathrm{C}$ for $1 \mathrm{~h}$, and then at $20{ }^{\circ} \mathrm{C}$ for $2 \mathrm{~h}$. The film preparation is described in more detail in the Supporting Information.

To retain the functional $\mathrm{BCP}$ template within the mesopores, the calcination temperature was limited to a maximum temperature of $200{ }^{\circ} \mathrm{C}$ for $2 \mathrm{~h}$, in agreement with the thermal degradation profiles measured by thermal gravimetric analysis (TGA) of the respective BCPs (Figure S2). The properties of the prepared $\mathrm{BCPs}$, as well as the resulting mesoporous films under filled and empty conditions are summarised in Table 1.

In all cases, a crack-free mesoporous structure is obtained with pore diameters ranging from approximately 4-8 $\mathrm{nm}$ as indicated by the SEM and TEM micrographs, respectively (Figure 2) and supported by GISAXS (Figure S14, S15), with a film thickness varying between 90 and $130 \mathrm{~nm}$ according to ellipsometry (Table 1, Entry (i)). In addition, the film morphology can be easily adjusted and tuned by changing the hydrophobic to hydrophilic ratio $\left(M_{1} / M_{2}\right)$ of the templating agent, where Film $A$ and $\mathrm{C}$ present similar film structures when compared to Film B. For additional information, see Table S2. 


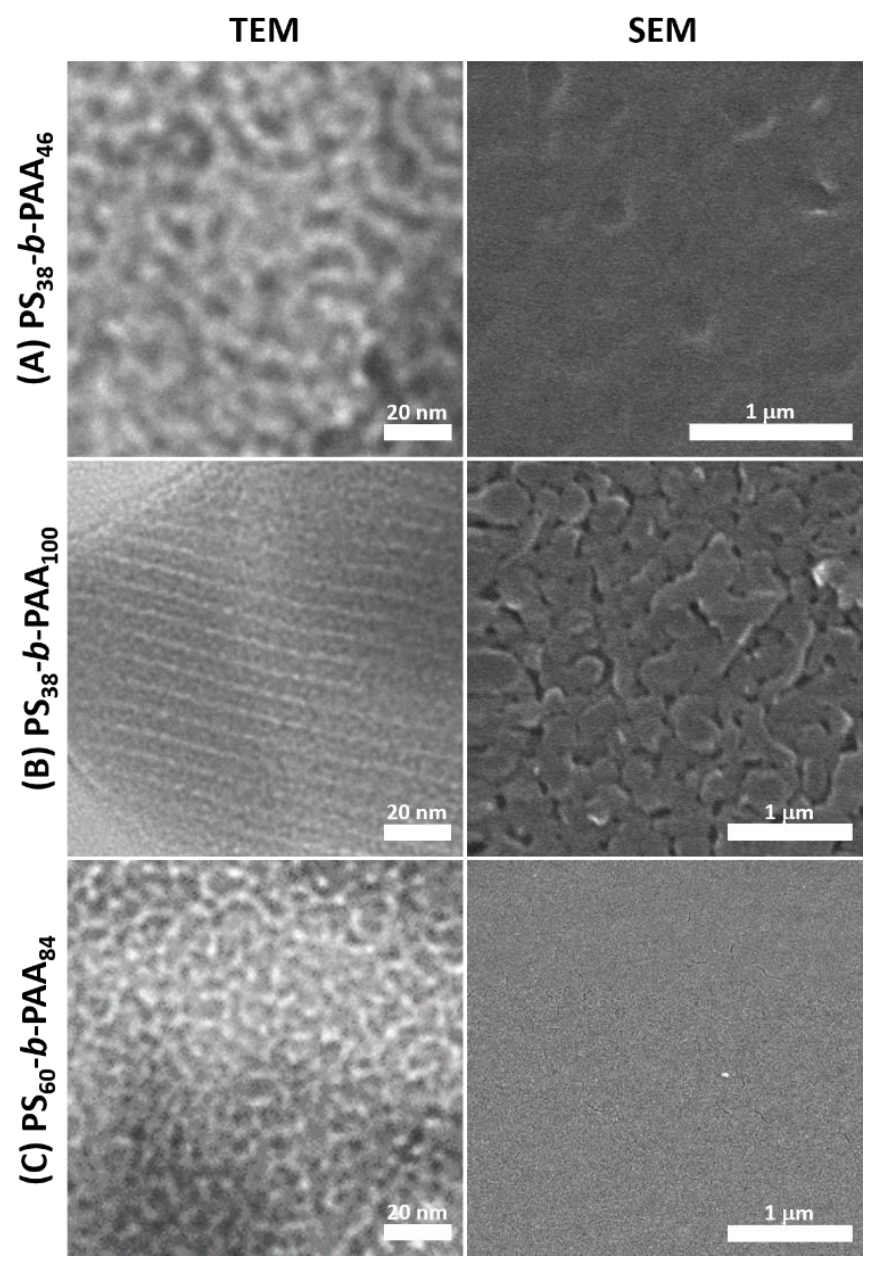

Figure 2 TEM and SEM micrographs of mesoporous silica films templated with (A) $\mathrm{PS}_{38}-b-\mathrm{PAA}_{46}$, (B) $\mathrm{PS}_{38}-b$-PAA 100 , and (C) $\mathrm{PS}_{60}-b-\mathrm{PAA}_{84}$ with approximate pore diameters of 4,7 , and $4 \mathrm{~nm}$, respectively. The SEM micrograph of (b) was conducted after exposure to a $0.01 \mathrm{M} \mathrm{HCl}$ ethanolic solution for 3 days.

The retention and integrity of the block copolymer upon the thermal consolidation step at $200{ }^{\circ} \mathrm{C}$ is further supported by the high macroscopic static contact angles of $75-85^{\circ}$ due to the presence of hydrophobic polystyrene within the mesopores; as well as by FTIR measurements (Figure 3) where the characteristic vibrational bands of both the PAA and PS blocks are clearly visible between 1700 and $1400 \mathrm{~cm}^{-1}$ (yellow inset).

In order to gain a better understanding of the mesoporosity of the films prepared, the BCP templates were removed by applying an additional thermal treatment at an elevated temperature of $350{ }^{\circ} \mathrm{C}$. The successful removal of the template is confirmed by FTIR, ellipsometry, and static CA measurements before and after this additional thermal treatment (Figure 3, Table 1). 


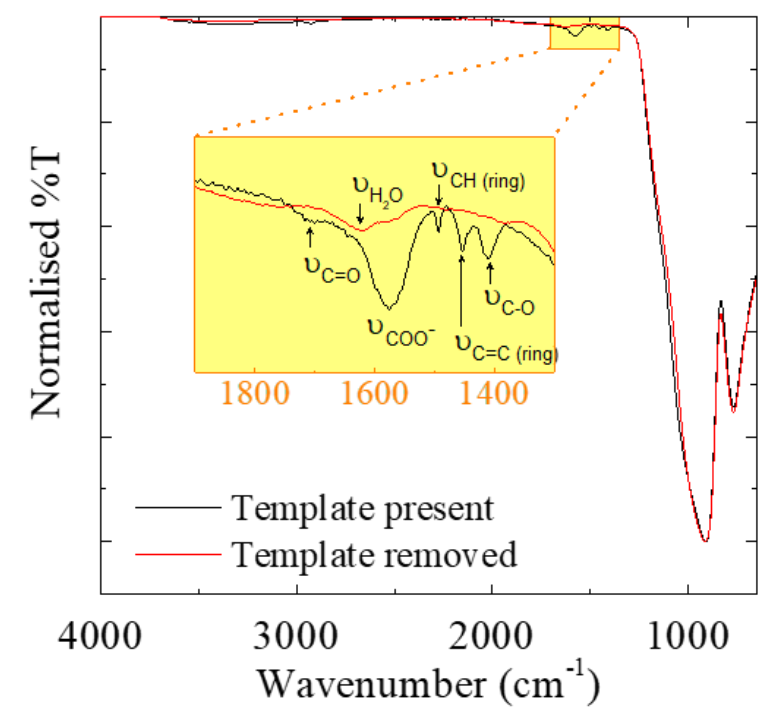

Figure 3 Typical ATR spectrum showing the presence of the functional block copolymer template $\left(\mathrm{PS}_{38}-b-\mathrm{PAA}_{46}\right)$ in the prepared mesoporous silica film after calcination at $200{ }^{\circ} \mathrm{C}$ (black trace), and after its removal with a subsequent heat treatment at $350{ }^{\circ} \mathrm{C}$ (red trace).

The filled OMS exhibits a refractive index of $\sim 1.5$, consistent with the presence of PS $(n \sim 1.6)$ and PAA $(n \sim 1.5)$ in the mesoporous silica. The film thickness shrinks between 7 and $23 \%$ depending on the template used upon an additional heat treatment at $350^{\circ} \mathrm{C}$ due the loss of the BCP structuring agent. This is further accompanied by a significant reduction in the refractive index to 1.2, which corresponds to highly porous silica with a free volume of 48 to $64 \%$ according to the Brüggemann effective medium approximation. ${ }^{21,22}$ The static contact angle is also significantly reduced from above $75^{\circ}$ to below $35^{\circ}$, comparable to the typical wetting behaviour observed for OMS films prepared using commercially available Pluronic ${ }^{\circledR}$ F-127. ${ }^{17}$

\section{Ionic permselectivity behaviour}

The electrochemical properties of the as-prepared mesoporous films with entrapped polymer were then investigated by cyclic voltammetry (CV) since the templating agents are successfully retained. Figure 4 shows how the polymer composition influences the $\mathrm{pH}$-dependent ionic permselectivity of mesoporous silica under highly filled conditions. The observed permselectivity behaviour predominantly arises due to the $\mathrm{BCP}$, with unhindered permselectivity towards both positive and negative species observed upon burning out the template at $350^{\circ} \mathrm{C}$ (Figure S5). The $\mathrm{pH}$-dependent CV traces are also provided in the ESI (Figure S6).

As expected from the variation in film morphology (Figure 2), very distinct behaviour is observed depending on the hydrophobic to hydrophilic ratio $\left(\mathrm{M}_{1} / \mathrm{M}_{2}\right)$, with Film $A$ and $\mathrm{C}$ displaying comparable permselectivity with incremental changes in $\mathrm{pH}$. These films are cation-selective above $\mathrm{pH} 9$ due to the presence of negatively charged silanol groups on the channel surface, and the deprotonated acrylic acid units of the BCP template. Electrostatic repulsion is expected to hinder the swelling of the PAA chains into the pore, ${ }^{23}$ and hence results in channel widening and unhindered transport of positive probe molecules. Acid-base equilibria shift under confinement, ${ }^{24-26}$ and also depend on polymer structure and functionality ${ }^{27}$ to suppress unfavourable electrostatic interactions. ${ }^{23}$ This explains the disparity between the bulk $\mathrm{p} K_{\mathrm{a}}$ of PAA of $\sim 4.75,{ }^{27}$ and its block copolymer with styrene of $6.3,{ }^{27}$ when compared to a value of $\sim 8-9$ when confined in the $\sim 4 \mathrm{~nm}$ pores of Film $A$ and $C$. In addition, increasing the overall molecular weight and AA content in Film C compared to Film A, results in the complete exclusion of negative species irrespective of $\mathrm{pH}$ due to pore blocking, wetting, and electrostatics. 


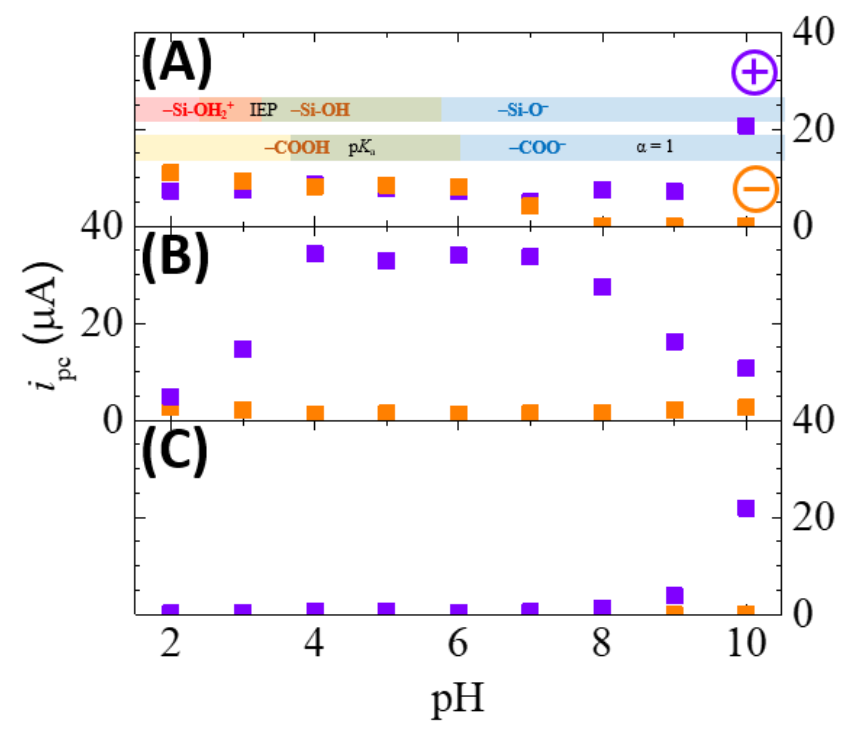

Figure 4 Cathodic peak current, $i_{\mathrm{pc}}$, of mesoporous silica films with increasing $\mathrm{pH}$ containing (A) $\mathrm{PS}_{38}-b$-PAA 46 , (B) $\mathrm{PS}_{38}-b$ $\mathrm{PAA}_{100}$, and (C) $\mathrm{PS}_{60}-b-\mathrm{PAA}_{84}$. The $\mathrm{CV}$ traces were recorded at a scan rate of $100 \mathrm{mV} \mathrm{s}^{-1}$ in a $100 \mathrm{mM} \mathrm{KCl}$ electrolyte containing $1 \mathrm{mM}\left[\mathrm{Fe}(\mathrm{CN})_{6}\right]^{4-/ 3-}$ (orange) or $\left[\mathrm{Ru}\left(\mathrm{NH}_{3}\right)_{6}\right]^{2+/ 3+}$ (blue) probe molecules.

Marked differences in permselectivity are observed upon decreasing the hydrophobic to hydrophilic ratio in Film B. Positive probe molecules still present higher mobility under extreme basic conditions compared to extreme acidic conditions; however, there is an additional enhancement in the electrochemical properties at intermediate $\mathrm{pH}$ values ranging between $\mathrm{pH} 4$ and 8 , with the cathodic peak current increasing by a factor of 3 . Zhu and coworkers, ${ }^{27}$ described how the behaviour of BCPs of styrene and acrylic acid behave in solution with increasing $\mathrm{pH}$; they present as compact micelles below $\mathrm{pH} 4$, and increase rapidly between $\mathrm{pH} 4$ and 6 to a maximum extended size. The increasing flow of positive charges from $\mathrm{pH} 2$ to 4 towards a maximum $i_{\mathrm{pc}}$ of $34 \mu \mathrm{A}$ is expected to result from an increasingly negatively-charged pore wall and the wider channels of $8 \mathrm{~nm}$ compared to film $A$ and $C$ in the presence of a compact micelle structure. After $\mathrm{pH} 7$, the acrylic acid moieties begin to deprotonate, causing the peak current to decrease. These results indicate that permselectivity under highly filled conditions results from a complex interplay between various parameters: polymer conformation and swelling, channel diameter and wetting, mesopore surface charge, and film morphology. The tortuosity of the films was further assessed to determine whether the films are accessible under filled and empty conditions (Figure S12).

Furthermore, the reversibility of this on-off gating behaviour was verified by monitoring the electrochemical signal whilst cycling between acidic and basic conditions. Figure 5 presents the cathodic peak currents, $i_{p c}$, of single layer mesoporous silica films containing the physically entrapped $\mathrm{PS}_{38}-b-\mathrm{PAA}_{100}$ template (Film B). These results clearly show these functionalised mesopores exhibit remarkable reversible permselectivity with changes in $\mathrm{pH}$, switching between cation- and anionselective under basic and acidic conditions, respectively. This behaviour can be predominantly attributed to electrostatics, with negatively charged silanol groups on the mesochannel surface and deprotonated acrylic acid moieties under highly basic conditions, resulting in an increased transport of positively-charged probe molecules, whilst precluding negatively-charged species from entering the pores. PAA is also known to exhibit $\mathrm{pH}$-dependent hysteresis when confined at high density within nanopores due to the compact configurations adopted through the formation of $\mathrm{H}$-bonds between adjacent AA moieties. ${ }^{23}$ This may explain the decreasing and increasing $i_{\mathrm{pc}}$ observed for positive and negative probes molecules, respectively. It should also be noted that for longer experimental timescales under extreme $\mathrm{pH}$ conditions, broadening of the cyclic voltammograms has been reported due to degradation. ${ }^{28}$ 


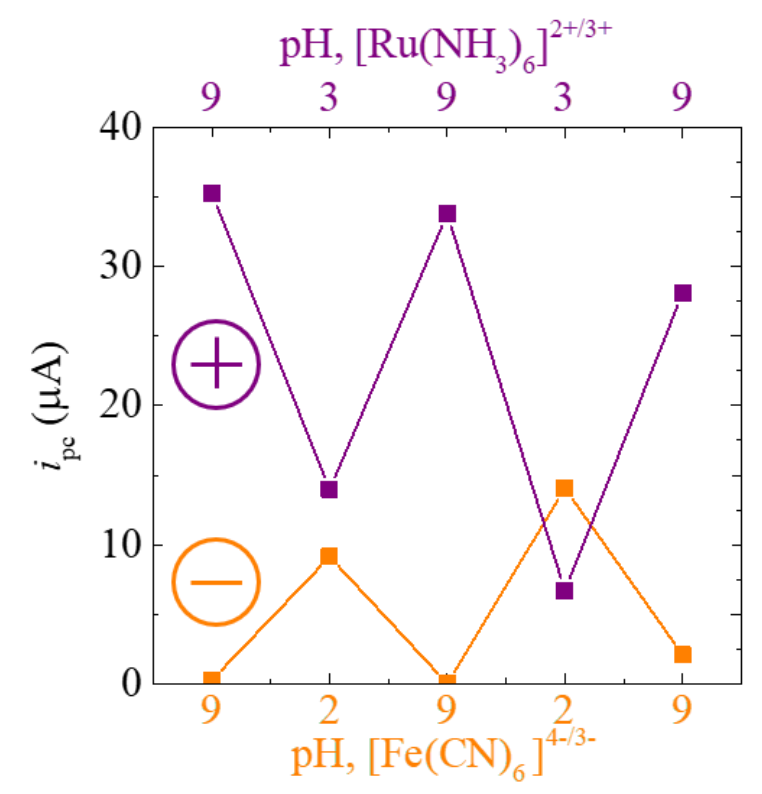

Figure 5 Reversible ionic permselectivity of mesoporous silica containing entrapped $\mathrm{PS}_{38}-b-\mathrm{PAA}_{100}$. The cathodic peak current, $i_{\mathrm{pc}}$, results from cyclic voltammetry recorded at a scan rate of $100 \mathrm{mV} \mathrm{s}^{-1}$ in a $100 \mathrm{mM} \mathrm{KCl}$ electrolyte containing either $1 \mathrm{mM}$ $\left[\mathrm{Fe}(\mathrm{CN})_{6}\right]^{4-/ 3-}$ or $\left[\mathrm{Ru}\left(\mathrm{NH}_{3}\right)_{6}\right]^{2+/ 3+}$ as probe molecules under acidic and basic conditions.

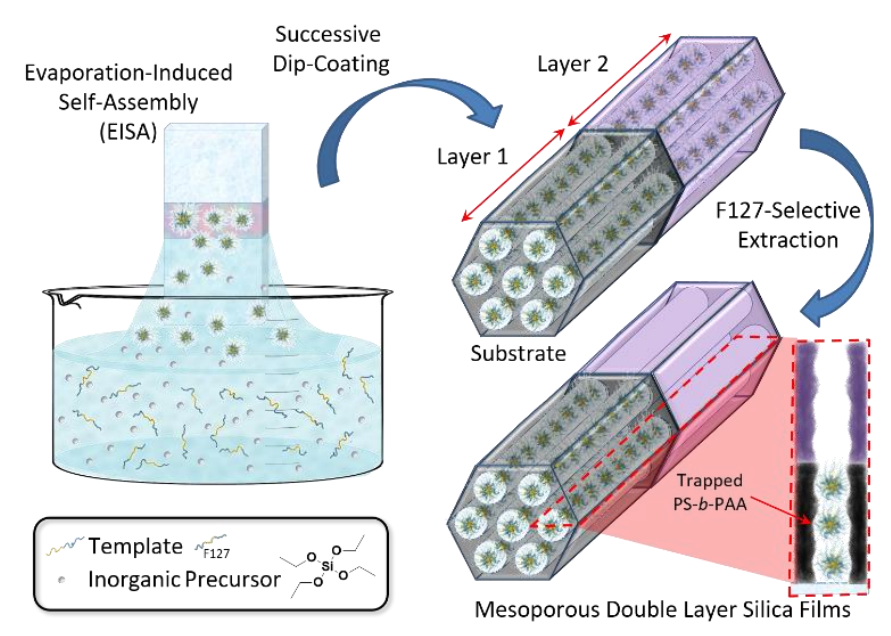

Figure 6 Synthetic approach towards the preparation of step-gradient films by sequential dip-coating and selective extraction of Pluronic ${ }^{\circledR}$ F127 in acidic ethanol for 3 days. This scheme is an idealised depiction of how the porous structure is formed, the structure achieved may deviate from the structure depicted here.

\section{Local Polymer Functionalisation and the Formation of Step-Gradient Films}

To demonstrate the potential of this approach for local polymer functionalisation, multilayer films were prepared exploiting the tolerance of the prepared BCP to ethanol compared to the commercially available template Pluronic ${ }^{\circledR}$ F127 (Figure S7). This concept is depicted in Figure 6. Two systems were attempted. In both cases, the first layer dip-coated was templated by $\mathrm{PS}_{38}-b-\mathrm{PAA}_{100}$ before a second layer of either mesoporous silica, $\mathrm{mSiO}_{2}$ (Table S3, Entry A) or mesoporous silica containing cocondensed amino groups (APTES) (Table S3, Entry B) was applied templated by F127. The F127 template was then selectively removed from the top layer by solvent extraction in acidic ethanol for 3 days. Ellipsometry and FTIR results of the respective single and double layer films confirm the successful confinement and retention of the functional BCP within the first layer following solvent extraction to prepare step-gradients (Figure S8, Table S3). Step-gradients, particularly with nanoscale resolution, have great potential to mimic the almost unfathomable precision displayed by nature to direct, gate, and selectively transport species across membranes to fulfil a specific function in the 
absence of an external force through the generation of an intrinsic electroosmotic flow. Mesoporous materials that are locally functionalised with charge-switchable, responsive polymers will take us one step closer in achieving precise transport control for the design of new advanced materials, not limited to lab-on-chip devices. Detailed results are discussed in the ESI.
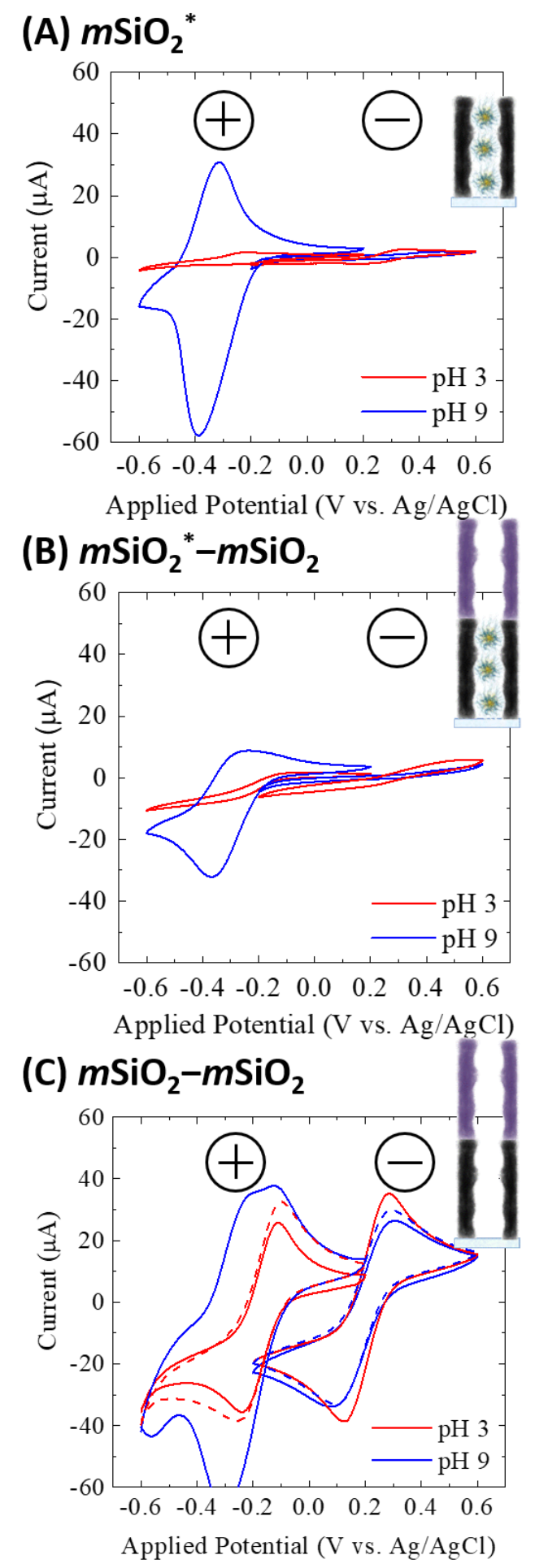

Figure 7 Cyclic voltammograms of (a) single layer mesoporous silica containing $\mathrm{PS}_{38}-b-\mathrm{PAA}_{100}$ in comparison to double layer films (b) with and (c) without $\mathrm{PS}_{38}-b$-PAA $A_{100}$ in the bottom layer. The second layer was structured using Pluronic ${ }^{\circ} \mathrm{F}-127$, and this was removed by solvent extraction. The $\mathrm{CV}$ traces were recorded at a scan rate of $100 \mathrm{mV} \mathrm{s}^{-1}$ in a $100 \mathrm{mM} \mathrm{KCl}$ electrolyte containing $\left[\mathrm{Fe}(\mathrm{CN})_{6}\right]^{4-/ 3-}$ or $\left[\mathrm{Ru}\left(\mathrm{NH}_{3}\right)_{6}\right]^{2+/ 3+}$ at a concentration of $1 \mathrm{mM} .\left(^{*}\right)$ indicates the functional BCP is present within the material. 
The electrochemical properties of the prepared step-gradient films were then examined via cyclic voltammetry (Figure 7, Figure S9). Under highly basic conditions, a peak broadening and shift in the oxidation peak of $\left[\mathrm{Ru}\left(\mathrm{NH}_{3}\right)_{6}\right]^{2+/ 3+}$ to lower potentials is apparent, and more pronounced under filled conditions for both the single and double layer films. In addition, negative probes are also excluded due to electrostatics. Such preconcentration behaviour and electrostatic exclusion is expected and quite typical for confined mesoporous materials with narrow pores and/or necks, such as under BCPfilled conditions. ${ }^{28}$

The $m \mathrm{SiO}_{2}{ }^{*}-m \mathrm{SiO}_{2}$ double layer film (Figure $7($ b)) displays similar permselectivity to both cations and anions compared to single layer block copolymer filled mesoporous silica, $\mathrm{mSiO}_{2}{ }^{*}$ (Figure $7(\mathrm{a})$ ), with a notable reduced peak current towards positive species, whilst the incorporation of 25 mol\% APTMS relative to TEOS in the second layer (Figure S9(c)) precludes both positive and negative ions irrespective of $\mathrm{pH}$, with cathodic peak currents close to $0 \mu \mathrm{A}$. The exclusion of both cations and anions likely arises from a combination of electrostatics and wetting. In both systems, layer infiltration and/or pore mismatch between layers can be excluded for the observed permselectivity of the double layer films, as the removal of all organic material by heating to $350{ }^{\circ} \mathrm{C}$ results in permselectivity typical of unfunctionalised mesoporous silica ((Figure 7(c) and Figure S9(d)). ${ }^{27}$ These preliminary results show how control over local functions can be used to influence the permselectivity of porous materials, and their potential application as molecular sieves, or in lab-on-chip and sensor devices, and demonstrate the potential of step-gradients for molecular transport design.

\section{Conclusions}

In summary, a series of well-defined and functional block copolymers of styrene and acrylic acid was accessed via a simple polymerisation and deprotection approach. These stimuli-responsive block copolymers successfully templated and functionalised mesoporous silica films through entrapment in a simple and novel one-pot procedure that display reversible on-off permselectivity to both positive and negative species with $\mathrm{pH}$ under an unprecedented degree of pore filling that is difficult, if not impossible, to achieve post-film formation. Furthermore, local polymer functionalisation is achievable through the preparation of multilayer films by the selective removal of a commercial template (F127) as confirmed by ellipsometry, FTIR, CV, and static CA measurements to form step-gradient films for fine-tuning ionic permselectivity.

\section{Conflicts of interest}

There are no conflicts of interest to declare.

\section{Acknowledgements}

The authors thank the Boehringer Ingelheim Stiftung for providing financial support for this project through the Exploration Grant. The technical facilities at the Technische Universität Darmstadt must also be acknowledged: Mrs. Kunz for TEM measurements; Heike Herbert for SEC sample preparation and analysis; Prof. Markus Biesalski for access to various characterisation equipment (CA, IR), Mathias Stanzel for selected CV measurements, Nicole Herzog for DLS measurements in the Laboratories of Dr. Markus Gallei, and Lucy Zhao as well as Laura Despot for additional SEM measurements and additional film preparation for GISAXS. We thank Prof. Regine v. Klitzing (Physics Department Technische Universität Darmstadt) for arranging access to GISAXS facilities and for helpful discussions. Prof. Stühn (Physics Department, Technische Universität Darmstadt) is also acknowledged for helpful discussion with respect to GISAXS experiments. Rigaku is gratefully acknowledged for GISAXS measurements. In addition, Dr. J. C. Tom acknowledges Dr. Athina Anastasaki for additional support concerning SET-LRP conditions and technique. This study represents preliminary work for an ERC Starting Grant (grant agreement number No 803758). 


\section{Notes and references}

1 F. Yan, X. Lin and B. Su, Analyst, 2016, DOI: 10.1039/C6AN00146G.

2 M. C. Fuertes, F. J. López-Alcaraz, M. C. Marchi, H. E. Troiani, V. Luca, H. Míguez and G. J. A. A. SolerIllia, Adv. Funct. Mater., 2007, 17, 1247.

3 M.-H. Sun, S.-Z. Huang, L.-H. Chen, Y. Li, X.-Y. Yang, Z.-Y. Yuan and B.-L. Su, Chem. Soc. Rev., 2016, $45,3479$.

4 J. Wei, Z. Sun, W. Luo, Y. Li, A. A. Elzatahry, A. M. Al-Enizi, Y. Deng and D. Zhao, Journal of the American Chemical Society, 2017, 139, 1706.

5 P. Xu, C. Chen and X. Li, Sci. Rep., 2015, 5, 17171.

6 M. Bathfield, J. Reboul, T. Cacciaguerra, P. Lacroix-Desmazes and C. Gérardin, Chem. Mater., 2016, 28, 3374 .

7 N. Baccile, J. Reboul, B. Blanc, B. Coq, P. Lacroix-Desmazes, M. In and C. Gérardin, Angewandte Chemie International Edition, 2008, 47, 8433.

8 C. J. Brinker, Y. Lu, A. Sellinger and H. Fan, Adv. Mater., 1999, 11, 579.

9 Y. Deng, J. Wei, Z. Sun and D. Zhao, Chem. Soc. Rev., 2013, 42, 4054.

10 G. J. A. A. Soler-Illia and O. Azzaroni, Chem. Soc. Rev., 2011, 40, 1107.

11 A. Feinle, M. S. Elsaesser and N. Husing, Chem. Soc. Rev., 2016, DOI: 10.1039/C5CS00710K.

12 N. Pal and A. Bhaumik, Adv. Colloid Interface Sci., 2013, 189-190, 21.

13 B. Sanz, N. Ballard, J. M. Asua and C. Mijangos, Macromolecules, 2017, 50, 811.

14 J. Tom, R. Brilmayer, J. Schmidt and A. Andrieu-Brunsen, Polymers, 2017, 9, 539.

15 E. Molina, J. Warnant, M. Mathonnat, M. Bathfield, M. In, D. Laurencin, C. Jérôme, P. LacroixDesmazes, N. Marcotte and C. Gérardin, Langmuir, 2015, 31, 12839.

16 M. Bathfield, J. Warnant, C. Gérardin and P. Lacroix-Desmazes, Polym. Chem., 2015, 6, 1339.

17 D. R. Ceratti, M. Faustini, C. Sinturel, M. Vayer, V. Dahirel, M. Jardat and D. Grosso, Nanoscale, 2015, 7, 5371.

18 J. Liu, S. Bai, Q. Jin, C. Li and Q. Yang, Chemical Science, 2012, 3, 3398.

19 D. Niu, Z. Ma, Y. Li and J. Shi, Journal of the American Chemical Society, 2010, 132, 15144.

20 N. Steunou, S. Förster, P. Florian, C. Sanchez and M. Antonietti, Journal of Materials Chemistry, 2002, 12, 3426.

21 C. Boissiere, D. Grosso, S. Lepoutre, L. Nicole, A. B. Bruneau and C. Sanchez, Langmuir, 2005, 21, 12362.

22 A. Brunsen, A. Calvo, F. J. Williams, G. J. A. A. Soler-Illia and O. Azzaroni, Langmuir, 2011, 27, 4328. 23 J. L. Weidman, R. A. Mulvenna, B. W. Boudouris and W. A. Phillip, Journal of the American Chemical Society, 2016, DOI: 10.1021/jacs.6b01618.

24 R. Nap, P. Gong and I. Szleifer, J. Polym. Sci., Part B: Polym. Phys., 2006, 44, 2638.

25 M. Tagliazucchi, O. Azzaroni and I. Szleifer, Journal of the American Chemical Society, 2010, 132, 12404.

26 R. J. Nap, M. Tagliazucchi and I. Szleifer, J. Chem. Phys., 2014, 140.

27 Y. Zhu, C. Yi, Q. Hu, W. Wei and X. Liu, Phys. Chem. Chem. Phys., 2016, 18, 26236.

28 S. Alberti, P. Y. Steinberg, G. Giménez, H. Amenitsch, G. Ybarra, O. Azzaroni, P. C. Angelomé and G. J. A. A. Soler-Illia, Langmuir, 2019, 35, 6279. 